\section{Cannabis based medicines and cannabis dependence: A critical review of issues and evidence}

\author{
Anne K Schlag1,2(D), Chandni Hindocha ${ }^{3-5}\left(\mathbb{D}\right.$, Rayyan Zafar ${ }^{1,2}$, \\ David J Nutt ${ }^{1,2}$ and H Valerie Curran ${ }^{3,5}$
}

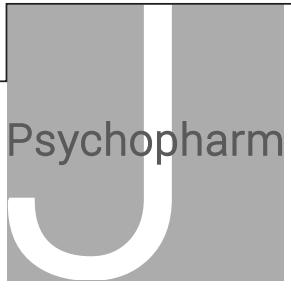

Journal of Psychopharmacology 1-13

(c) The Author(s) 2021

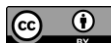

Article reuse guidelines: sagepub.com/journals-permissions DOI: $10.1177 / 0269881120986393$ journals.sagepub.com/home/jop

(S)AGE

\begin{abstract}
Cannabis has been legalised for medical use in an ever-increasing number of countries. A growing body of scientific evidence supports the use of medical cannabis for a range of therapeutic indications. In parallel with these developments, concerns have been expressed by many prescribers that increased use will lead to patients developing cannabis use disorder. Cannabis use disorder has been widely studied in recreational users, and these findings have often been projected onto patients using medical cannabis. However, studies exploring medical cannabis dependence are scarce and the appropriate methodology to measure this construct is uncertain. This article provides a narrative review of the current research to discern if, how and to what extent, concerns about problems of dependence in recreational cannabis users apply to prescribed medical users. We focus on the main issues related to medical cannabis and dependence, including the importance of dose, potency, cannabinoid content, pharmacokinetics and route of administration, frequency of use, as well as set and setting. Medical and recreational cannabis use differs in significant ways, highlighting the challenges of extrapolating findings from the recreational cannabis literature. There are many questions about the potential for medical cannabis use to lead to dependence. It is therefore imperative to address these questions in order to be able to minimise harms of medical cannabis use. We draw out seven recommendations for increasing the safety of medical cannabis prescribing. We hope that the present review contributes to answering some of the key questions surrounding medical cannabis dependence.
\end{abstract}

\title{
Keywords
}

Medical cannabis, tetrahydrocannabinol, cannabidiol, dependence, cannabis use disorder

\section{Introduction}

\section{What lessons can we learn from history?}

Cannabis is arguably the world's oldest medicine. It has been used medically for millennia especially in China and India. It was introduced into Western medicine in the mid-19th century as various tinctures and extracts. The medical use of cannabis in the West declined in the early 20th century, partly due to extreme variations in effects depending on where, how, when and what strain of plant material had been grown. We now understand these variations as deriving from different combinations and concentrations of over 140 cannabinoids and more than 100 different terpenoids found in different strains of the cannabis plant.

A new cycle has begun for the use of cannabis derivatives as medicines, this time with more consistency than in the past. Interest in the therapeutic benefits of medical cannabis has grown rapidly in the past 20 years, with patients using cannabinoids to treat a variety of conditions, from chronic pain, cancer and neurological disorders to anxiety and sleep disorders (Schlag et al., 2020; United Patients' Alliance [UPA], 2018). The structures of chemical compounds derived from cannabis are now known, their mechanisms of action in the nervous system are being elucidated as we learn more about our endogenous cannabinoid system, and treatment effectiveness and safety are increasingly being evaluated scientifically.

Clearly, a more widespread use of cannabis is for recreation and pleasure. In reality, the divide between recreational use and medical use of a drug is quite blurred, and history is dotted with drugs that have been used for both purposes. Opiates have been used medically to reduce pain and recreationally for pleasure; benzodiazepines to reduce anxiety and promote sleep for patients and recreational users alike. Alcohol, our most common recreational drug, was once used medically as an anaesthetic and analgesic before more effective drugs emerged. Amphetamines have been used medically for Attention Deficit Hyperactivity Disorder (ADHD) (and appetite suppression) and recreationally as 'speed'; ketamine has been used since 1964 as anaesthetic, since the 1990s as a recreational drug and since 2019 as a licensed, rapid-acting anti-depressant for individuals resistant to other treatments.

We can learn some lessons from how medical use of opiates, benzodiazepines and other psychoactive drugs lead to dependence

\footnotetext{
${ }^{1}$ Drug Science, St Peter's House, London, UK

${ }^{2}$ Neuropsychopharmacology Unit, Centre for Psychiatry, Imperial College London, London, UK

${ }^{3}$ Clinical Psychopharmacology Unit, University College London, London, UK

4Translational Psychiatry Research Group, Research Department of Mental Health Neuroscience, University College London, London, UK ${ }^{5}$ University College Hospital National Institute of Health Research (NIHR) Biomedical Research Centre, London, UK
}

Corresponding author:

H Valerie Curran, Clinical Psychopharmacology Unit, University College London, Gower St, London WC1E 7HB, UK.

Email:v.curran@ucl.ac.uk 
in some patients but not others. However, medical cannabis use may well differ, in part because cannabis is a potential treasure chest of many pharmacologically different medicines. It might also differ in that some cannabinoids like tetrahydrocannabinol (THC) in higher doses and frequent usage promote dependence whilst cannabidiol (CBD), may have anti-addictive properties (Freeman et al., 2020; Morgan et al., 2010). This means that carefully balancing the cannabinoid content of cannabis-based medicines could potentially block the development of dependence.

\section{Aims and rationale of the current review}

Research on medical cannabis dependence is still in its infancy. Most of the studies on cannabis dependence have been conducted in relation to recreational use, which substantially differs from the medical application of cannabis. The differences between medical and recreational cannabis use and users highlight the challenges of simply extrapolating findings from the recreational cannabis literature. Many questions about the potential for medical cannabis use to lead to dependence remain to be answered. It is imperative to address these questions in order to be able to minimise harms of medical cannabis use. Here, we offer a narrative review of the literature and consider to what extent research on recreational cannabis dependence might be applied to medical cannabis dependence.

\section{What are cannabis-based medicines?}

In recent decades, many US states and over 20 countries globally, have instigated regulatory regimes of medical use of the plant and the World Health Organization (WHO) has now accepted its medical use (World Health Organization [WHO], 2019). However, there are significant differences in the way that medical cannabis policies are enacted and there are no international standards on the best way to regulate this. Whilst appreciating that definitions, regulations and subsequent access to medical cannabis differ between countries (Schlag, 2020), the current article adopts a UK perspective for these specifics only, although the overall conclusions and recommendations will have wider applicability.

There is often uncertainty about what exactly defines cannabis, a cannabinoid, or THC, as well as the different formulations available. It is vital to distinguish between CBD (not a controlled drug in the UK) and formulations of CBD plus THC to ensure a clear understanding of the distinctions in active ingredients and in formulations as these relate to specific applications. Freeman et al. (2019a) provide a helpful summary, highlighting that cannabis is not one medicine but rather a whole family of medicines. We focus on cannabis-based medicinal products (CBMPs) as defined by the Misuse of Drugs (Amendments) (Cannabis and Licence Fees) (England, Wales and Scotland) Regulations 2018:

[A] cannabis-based product for medicinal use in humans means a preparation or other product... which a) is or contains cannabis, cannabis resin, cannabinol or a cannabinol derivative (not being dronabinol or its stereoisomers); (b) is produced for medicinal use in humans; and (c) is (i) a medicinal product, or (ii) a substance or preparation for use as an ingredient of, or in the production of an ingredient of, a medicinal product. 2019)

(National Institute for Health and Care Excellence [NICE],

Cannabis-based medicines in the UK. Currently there are four licenced CBMPs that can be prescribed by specialist doctors. These are:

1. Two THC-based medicines: dronabinol - licensed for appetite loss in acquired immune deficiency syndrome (AIDS) and as an anti-emetic in chemotherapy and nabilone licensed for nausea in individuals receiving chemotherapy.

2. Combined THC: CBD medicines: Sativex - for muscle spasticity in multiple sclerosis

3. CBD-based medicines: Epidiolex (99.8\% CBD with less than $0.1 \%$ THC) - for two rare childhood epilepsies (Lennox-Gastaut and Dravets syndrome) (NICE, 2019).

There are a multitude of other unlicensed cannabis-based products (e.g. oils, herbal cannabis) that are produced to Good Manufacturing Practices (GMP) standard and so can now be prescribed in the UK.

\section{Addiction vs dependence: chewing the 'CUD'}

Addiction, dependence, abuse, substance use disorder - there is a terminological quagmire in struggling to de-stigmatise by changing names across time. Here, we define addiction as an acquired, chronic, relapsing disorder that is characterised by a powerful motivation to continually engage in an activity despite persistent negative consequences. Dependence on a drug can occur without these drug-seeking activities or such persistent negative consequences. Dependence is therefore a more appropriate term when referring to medicinal cannabis use.

Addictive drugs can all cause similar changes by hijacking brain circuits underpinning reward, salience, impulsivity, compulsivity, learning and memory (Everitt et al., 2016; Goldstein and Volkow, 2011; Koob et al., 2010; Nestler, 2005). The result is a dysregulation between regulatory executive 'top-down' control and 'bottom-up' reward and emotional drives. This imbalance gradually leads to a loss of control over impulsive and then compulsive drug seeking behaviours (Droutman et al., 2015).

Clinical problems associated with cannabis use were once diagnosed as either 'cannabis abuse' or 'cannabis dependence' in the Diagnostic and Statistical Manual for Mental Disorders, fourth edition, text revision (DSM-IV-TR). In the most recent version (DSM-5), these categories were amalgamated into a single diagnosis of 'cannabis use disorder' (CUD), as described in Table 1. DSM-5 defines CUD as: 'A problematic pattern of cannabis use leading to clinically significant impairment or distress, as manifested by at least two of the symptoms from the three lists in Table 1, occurring within a 12-month period' (American Psychiatric Association [APA], 2013). Mild CUD is associated with having two or three of these symptoms, moderate CUD with four or five symptoms, and severe CUD with six or more symptoms. One advantage of combining abuse and dependence criteria is the provision of a clearer continuum between mild and severe presentations as previously all cases of dependence also met criteria for abuse. Another advantage is that dependence on a medicine is often a common and 'normal' situation. For example, stopping the use of a prescribed pain killer does not necessarily lead to 


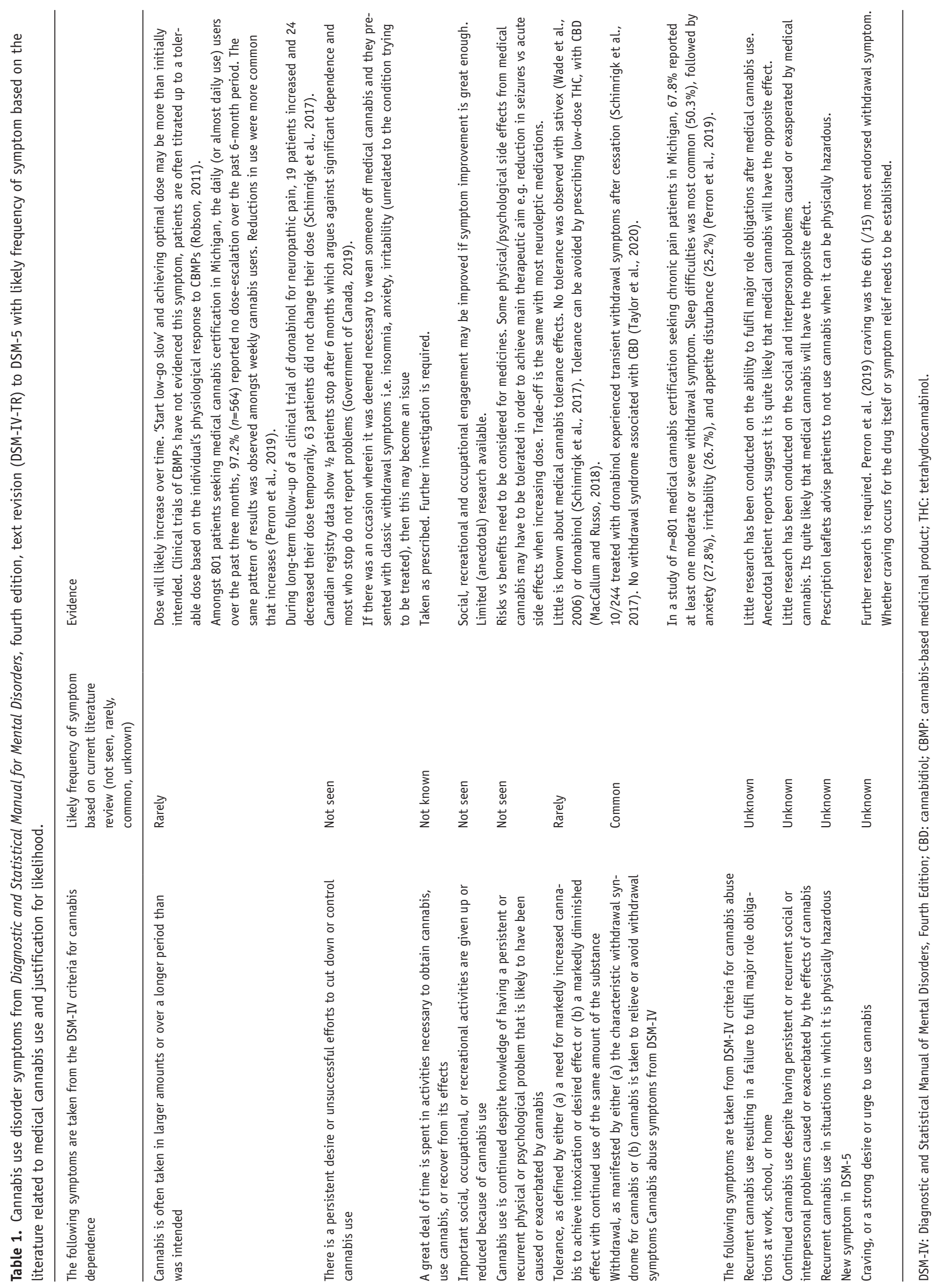


drug-seeking behaviours but individuals may be dependent upon them for pain relief (Supplementary Table 1).

For recreational users, the estimated chances of becoming dependent on cannabis after any lifetime exposure is $8.9 \%$, which is considerably lower than for cocaine (20.9\%), alcohol (22.7\%) or tobacco (67.5\%) (Lopez-Quintero et al., 2011). Nevertheless, the clinical need for treatment of cannabis dependence is substantial and increasing across North America, Europe and Oceania (United Nations Office on Drugs and Crime [UNODC], 2015). In Europe, cannabis now accounts for more first-time entrants to drug treatment services than any other illicit drug (EMCDDA, 2015). Globally, the United Nations reports that cannabis dependence is now the primary reason for drug treatment across the world $(39 \%)$, surpassing numbers receiving opioid treatment (33\%) (UNODC, 2017).

A specific cannabis withdrawal syndrome - one aspect of dependence - is well-recognised and affects around $50 \%$ of daily users and typically begins 1-2 days after cessation, peaks at 2-6 days and remits at 1-2 weeks (Budney et al., 2004). Prominent symptoms include craving, sleep problems, nightmares, anger, irritability, dysphoria and nausea (Allsop et al., 2011). This can be precipitated by the Cannabinoid 1 receptor (CB1) receptor antagonist rimonabant (Steward and McMahon, 2010). Cannabis withdrawal symptoms in humans correlate with reductions in brain CB1 receptor availability during acute abstinence (D'Souza et al., 2016).

Cannabis, THC and dependence. The main cannabinoid with psychoactive properties is THC, which was made a Schedule 1 drug under the United Nations Convention on Psychotropic Substances as it has the capacity to produce a state of dependence (United Nations, 1971). A wealth of pharmacological evidence supports the role of THC as the addictive agent within cannabis. THC produces the effects that recreational cannabis users seek; they report liking it and wanting more and this increases with acute THC dosage (Curran et al., 2002). In addition, cannabis with higher THC content (for example, $5 \%$ versus $2 \%$ ) produces stronger reinforcement in human choice paradigms (Justinova et al., 2005). THC binds to the CB1 receptor to exert its psychoactive effect and $\mathrm{CB} 1$ receptor antagonists have been found to precipitate withdrawal in mice that have been exposed to THC (Cook et al., 1998; Steward and McMahon, 2010). In addition, studies have found that acute administration of THC is reinforcing in humans whether or not CBD is co-administered (Haney et al., 2016; Hindocha et al., 2015). As the reinforcement of drug use is considered to be one component in the transition from voluntary to compulsive use (Everitt and Robbins, 2016), these findings suggest that cannabis with high THC content increases vulnerability to dependence. Indeed, clinically, increases in the number of new entrants into treatment for cannabis use disorder have followed increases in THC potency (Freeman et al., 2018). The risk of recreational cannabis dependence is more common with high potency THC strains with a low CBD content, large amounts consumed, high frequency use (heavy, daily) and with starting use early in adolescence (Curran et al., 2016).

The role of CBD. CBD has no abuse potential (WHO, 2018) which is why it has never been a controlled drug in the UK. $\mathrm{CBD}$ has a complex range of pharmacological actions. For example, although $\mathrm{CBD}$ has a low affinity for the $\mathrm{CB} 1$ receptor, it can attenuate $\mathrm{CB} 1$ receptor agonist effects in the brain even at low concentrations (Straiker et al., 2018; Tham et al., 2018). $\mathrm{CBD}$ also reduces the cellular re-uptake and hydrolysis of the brain's endogenous cannabinoid anandamide (AEA; also known as $\mathrm{N}$-arachidonylethanolamide) (Muniyappa et al., 2013; Pertwee, 2008). CBD has also been found to regulate mesolimbic dopamine activity (Murillo-Rodríguez et al., 2011) and attenuate substance-induced dysregulation of the mesolimbic circuitry (Renard et al., 2016). Consequently, the inclusion of CBD in all forms of legally prescribed medical cannabis provides grounds for a molecular mechanistic defence against dependence. There is some evidence that CBD may play an active role in pain reduction and may lead to a form of psychological dependence. However, this evidence is not consistent across studies (Argueta et al., 2020). Indeed, a recent randomised controlled trial (RCT) of three doses of CBD and matched placebo has found that CBD $(400,800 \mathrm{mg}$ daily over 4 weeks) leads to a reduction in daily cannabis use in men with CUD (Freeman et al., 2020).

Medical cannabis: evidence of dependence?. To date, there is very limited research investigating the relationship between medical cannabis use and dependence. There are three aspects of dependence that must be included when holistically considering medical cannabis use, namely: physical, psychological and medical. Physical dependence is characterised by withdrawal symptoms upon cessation of medication use. This occurs due to a physiological adaptation to the drug and the body's response to compensate for the drug's actions. The second aspect is psychological dependence which encompasses powerfully motivating cognitive processes that maintain drug consumption to avoid the anticipated negative consequences of stopping use (Nutt, 2003). Dependence as a medical diagnosis attempts to combine both physiological, psychological as well as behavioural aspects to dependence such as drug-seeking behaviours. This perspective allows for a multi-domain analysis of contributing and maintaining factors to dependence. Nonetheless, a nuanced examination of dependence domain-specific effects of medical cannabis is warranted to assess the extent of knowledge in the field and to highlight research gaps.

To date, the clinical assessment of problematic cannabis use has been largely informed by the Cannabis Use Disorder Identification Test short form (CUDIT-SF) (Bonn-Miller et al., 2016) as well as the Cannabis Use Disorder Identification Test revised (CUDIT-R). Both of these were designed to tap problematic use, including dependence, in recreational users. They were not intended nor validated for that purpose. To address this, several of us (HVC, $\mathrm{CH}, \mathrm{AKS}$ ) are currently developing a measure to specifically assess problematic medical cannabis.

Despite this paucity of evidence, the United Nations' Report of the International Narcotics Control Board for 2018 declared that dependence is a probable outcome of daily medical cannabis use and that the risk of dependence might be as high as one in three persons (United Nations, 2019). Those using THC related compounds daily (e.g. for chronic pain) may have a greater risk of dependence over those using it weekly for chemotherapyinduced nausea (United Nations, 2019). However, at present there is a lack of data to support these claims and they provide no structure as to how they might be substantiated.

From a scientific perspective to prove evidence of dependence we would need to see: 
Table 2. Characteristics of medical vs recreational use and users.

\begin{tabular}{|c|c|}
\hline Medical use & Recreational use \\
\hline $\begin{array}{l}\text { Often daily ( } 55.9 \% \text { of users report daily use, } 23.5 \% \text { report weekly use) } \\
\text { (Stewart, 2020) }\end{array}$ & $\begin{array}{l}\text { Full range from rarely to daily; only some daily users are } \\
\text { addicted (Cuttler and Spradlin, 2017) }\end{array}$ \\
\hline Various routes of administration (Borodovsky et al., 2016) & Often smoked with tobacco in the UK (Winstock et al., 2017) \\
\hline $\begin{array}{l}\text { Lower controlled dose of known quantity of cannabinoids/cannabis (Cash } \\
\text { et al., 2020) }\end{array}$ & $\begin{array}{l}\text { Higher THC dose, often unknown, cannabinoid content usu- } \\
\text { ally unknown (Cash et al., 2020) }\end{array}$ \\
\hline Regulated quality (e.g. cGMP) & Unknown quality \\
\hline Poorer general physical health (Lin et al., 2016) & Usually good general health (Lin et al., 2016) \\
\hline Poorer psychological well-being (Goulet-Stock et al., 2017) & $\begin{array}{l}\text { Generally good psychological well-being (Goulet-Stock et al., } \\
\text { 2017) }\end{array}$ \\
\hline Lower physical QoL scores & Generally normal range of $\mathrm{QoL}$ \\
\hline Higher age ( $>50$ years) (Turna et al., 2020) & Lower age (Winstock et al., 2019) \\
\hline Main aim to alleviate symptoms (Stith et al., 2018) & $\begin{array}{l}\text { Main aim enjoyment, relaxation, social effects (Geraint } \\
\text { et al., 2008) }\end{array}$ \\
\hline $\begin{array}{l}\text { Little desire to get 'high'. Represented in a sample of MS patients with high } \\
\text { drop out rate from Sativex (THC based medication) (Carotenuto et al., 2020) }\end{array}$ & Liking effects of THC (Osborne and Vogel, 2008) \\
\hline $\begin{array}{l}\text { Lower prevalence of substance use disorder (including alcohol) (Compton } \\
\text { et al., 2017) }\end{array}$ & Often other psychoactive drug use (Compton et al., 2017) \\
\hline
\end{tabular}

cGMP: current good manufacturing practice; QoL: quality of life; THC: delta-9-tetrahydrocannabinol; UK: United Kingdom.

1. Increased use over time consistent with tolerance. This would need to be independent of the intended therapeutic increase of dose.

2. Significant withdrawal symptoms when the drug is stopped. There are two withdrawal syndromes that we may see:

(a) Discontinuation syndrome: an appearance of symptoms that were not part of the original disorder for which the CBMP was prescribed include craving, sleep problems, nightmares, anger, irritability, dysphoria and nausea.

(b) Rebound syndrome: an increase in the severity of symptoms of the original condition.

3. Craving for the drug. This would be characterised by a loss of control over medication use. Even if medical cannabis may not be pleasurable it may still be craved once use is established, as can happen with other medicines such as opioids.

Table 1 lists the DSM-5 symptoms for recreational cannabis use which consist of previous diagnostic criteria for cannabis dependence and abuse from DSM-IV with the inclusion of the new DSM-5 criteria of 'craving'. Comparing dependence rates between medical and recreational users, Lin et al. (2016) used these criteria to define past year cannabis abuse or dependence and found that $10 \%$ of recreational users and $11 \%$ of medical users met the criteria for cannabis dependence. A similar prevalence of cannabis use disorders in people who use cannabis recreationally vs medically was found by Bonn-Miller et al. (2014). Yet looking at the applicability of these symptoms to medical cannabis use, our summary suggests that these criteria may not be the most suitable assessment of potential medical cannabis dependence.

The number of people dependent on cannabis (defined as people using prescribed cannabis outside of their medical dose and treatment regime) may well grow as medicinal cannabis use becomes more acceptable and the drug more accessible. There is conflicting evidence that this is already happening in the USA where some data has shown that adults in states that permit medical use of cannabis have higher rates of daily cannabis use and CUD than states that have not passed this legislation (Hasin et al., 2015, 2017). Conversely, other sources have shown that following medical cannabis enactment laws no significant changes were seen in CUD and there was no significant increase in cannabis consumption in younger age groups. There was however an increase in cannabis use in people aged $26+$ years (Mauro et al., 2018) which could be in part due to an increase in medical prescriptions, the majority of which are made for over $30 \mathrm{~s}$ (Fairman, 2016).

Interestingly, data from Canada has shown that since the legalisation of recreational cannabis there has been a fall in the number of sales for medical purposes, suggesting some users were accessing medical cannabis for non-medical needs and were now accessing cannabis via the recreational market (Government of Canada, 2019). In spite of this, we argue that medical cannabis diversion in the UK would be an unlikely scenario currently due to the significantly higher cost of medical cannabis compared with illicit supplies and the relatively low 'rewarding' effects of licenced CBMPs.

\section{Differences between medical and recreational users}

Medical and recreational cannabis users differ in the motivation and patterns of use of cannabis (Wang et al., 2008; please see Table 2 below). Medical cannabis users often have poorer general health (e.g. depression and anxiety, and registered disability status) than recreational users (Goulet-Stock et al., 2017; Lin et al., 2016). This is unsurprising as individuals using medical cannabis by definition have an underlying medical condition they are addressing through their use.

It must be acknowledged that the division between medical and recreational cannabis users is blurred at best as many medical users also use non-medically (Choi et al., 2017; Wall et al., 2019) 
and many recreational users self-medicate conditions such as social anxiety with cannabis.

Chronic pain is the most common condition for which patients seek medical cannabis (Boehnke et al., 2019). Chronic pain is often comorbid with depression and anxiety (Feingold et al., 2019). However, a comprehensive review of placebo-controlled studies of cannabis and CBMPs for pain, found that few assessed abuse liability (Cooper and Abrams, 2019). Feingold et al. (2017) found the prevalence of problematic medical cannabis use to be relatively high, with $21.2 \%$ (DSM-IV) and 10.6\% (modified Portnoy's Criteria (PC)) amongst chronic pain patients. Feingold et al. (2019) highlight that severe depression may be one risk factor for medical cannabis dependence among chronic pain patients.

Hasin et al. (2020) found that the prevalence of non-medical cannabis use and CUD was higher amongst people with chronic pain across a 10-year period in the USA. Problematic use was more common in patients using larger amounts for longer periods, reporting higher levels of depression or anxiety and using other drugs including alcohol. However, comparing the same population's problematic opioid use, problematic use of prescription opioids was far more prevalent than problematic medical cannabis use (Feingold et al., 2017).

It is important to interpret the (limited) evidence with caution and within its wider context. Dependence rates for medical users have to be contextualised firstly in terms of other drug use, (e.g. less dependence on more harmful drugs such as opioids (Feingold, 2017)) and secondly in terms of the patient's medical condition (e.g. if a chronic condition is successfully treated by medical cannabis, a degree of dependence might well be acceptable to users). It is important not to confuse the desire to continue taking a drug that treats chronic symptoms which re-emerge when the drug is stopped, with the craving of addiction: paracetamol for instance can be used repeatedly to treat chronic pain (Singh et al., 2017).

Although medical cannabis use may lead to dependence, it compares favourably in regards to safety and tolerability with other drugs, such as opioids, and it is important to weigh up the benefits of use vs the risk of dependence. Many of the conditions for which medical cannabis is used are chronic, highlighting the need for a medicine with a good safety profile. Especially for chronic pain patients, adverse effects may only play a limited role, even tolerance or dependence. Other medications currently used for chronic pain, such as pregabalin and opioids, have a higher potential for abuse and dependency, and may cause more severe withdrawal symptoms after cessation than medical cannabis (Edlund et al., 2014). When prescribing, physicians need to take this trade-off into consideration, particularly when use is long-term. In their long-term observational study of 180 chronic pain patients, Takakuwa et al. (2020) found that medical cannabis can indeed diminish prescription opioid usage, working as a preferred alternative to prescription opioids in over half of their patients.

The issue of CUD has become more relevant in relation to other emerging trends in drug dependence particularly the current opioid crisis in the USA. Here, there is a nationwide federal focus on prescription opioid harm reduction strategies, that includes alternative therapies for pain management, such as medical cannabis. There is a developing evidence base that some chronic pain patients are able to substitute opioids with medical cannabis (e.g. Bergeria et al., 2020; Takakuwa et al., 2020; Vyas et al., 2018). Furthermore, Piper et al. (2017) identified a reduction in opioid overdose deaths in those US states that legalised medical cannabis. In this arena it is vital that appropriate definitions of addiction and dependence to opioid substitute medicines are followed to avoid conflating opioid dependence with medical cannabis use.

Similarly, medical cannabis users often also have lower levels of alcohol-use disorders and non-cannabis drug use severity compared to recreational users (Lin et al., 2016; Wall et al., 2019; Woodruff et al., 2016) which might indicate that medical cannabis use may reduce ('substitute' for) other psychoactive substance use, including alcohol (Bonn-Miller et al., 2014; Loflin et al., 2017; Reiman, 2007). Again, relative dependence potential of the different drugs needs to be taken into account.

\section{Dose}

One of the primary issues with the potential for medical cannabis dependence is dosage. Since a standard dose or unit of cannabis does not yet exist, patients are often required to titrate their dose to their desired effect while trading off any negative effects. The patient rather than the doctor determines the correct dose. Unlike with standardised preparation of CBMPs, smoked flower is harder to titrate and quantify, especially for non-experienced users as demonstrated by studies in recreational users (Freeman et al., 2014). Several conceptual units have been developed for recreational cannabis use (Hindocha et al., 2018; Kögel et al., 2017). For example, Freeman and Lorenzetti (2019) define a standard unit as $5 \mathrm{mg}$ of THC whilst Chester et al. (2020) suggest that a standard unit should be the THC amount corresponding to the lowest dose that produces subjective effects.

When patients are prescribed Sativex, each $100 \mu \mathrm{L}$ spray contains $2.7 \mathrm{mg}$ THC and $2.5 \mathrm{mg} \mathrm{CBD}, 0.04 \mathrm{mg}$ ethanol and very small amounts of other cannabinoids (GWPharma, 2019). Thus, in its formulation and composition Sativex is very different to cannabis. The prescribing guidelines suggest that patients gradually titrate their dose (i.e. sprays per day) for the first two weeks, from 1-12 if needed. In routine clinical practice, the median number of sprays is four (equivalent to $10.8 \mathrm{mg}$ THC and $10 \mathrm{mg}$ $\mathrm{CBD}$ ), and in clinical trials, it was nine sprays. Therefore, just as one might self-titrate how much cannabis one inhales, the guidelines are defined to ensure patients can self-titrate to the amount they need.

A GW-Pharma sponsored study designed to identify the abuse liability of Sativex in recreational cannabis users compared four sprays, eight sprays and 16 sprays $(10.8,21.6$ and $43.2 \mathrm{mg}$ THC, respectively) of Sativex with two doses of dronabinol (20 $\mathrm{mg}$ and $40 \mathrm{mg}$ ) and placebo in a randomised order (Schoedel et al., 2011). Four sprays $(10.8 \mathrm{mg}$ ) of Sativex showed no more abuse liability ('drug liking', euphoria, subjective drug value) than placebo. Higher doses of eight and 16 sprays showed a greater liability for abuse than placebo. However, equivalent doses of dronabinol showed greater abuse liability than Sativex (Schoedel et al., 2011). Therefore, higher doses of dronabinol and Sativex are associated with abuse-related subjective effects. Moreover, in one study of cannabinoid replacement therapy, both dronabinol and Sativex had higher self-reports of liking than placebo (Allsop et al., 2015).

It should be noted that in these studies, the entire dose was given at once, whereas in routine clinical practice, single sprays are used throughout the day. Moreover, Schoedel et al.'s (2011) study was conducted with recreational cannabis users who could 
use cannabis in between sessions and are more likely to respond to different subjective effects than non-cannabis experienced patients with clinical disorders. For neither drug has abuse been observed in post-marketing research (Calhoun et al., 1998; Robson, 2011; Wade et al., 2006).

\section{Frequency of use}

A key issue in the debate of problematic (recreational) cannabis use, is the role of frequency of use because many people who use cannabis daily experience no clinical problems (Braidwood et al., 2018). Regarding medical use, patients often are titrating up to a higher dosage than recreational cannabis users, as they may be using throughout the day (Goulet-Stock et al., 2017; Roy-Byrne et al., 2015). Although daily cannabis use can be associated with a range of other risk factors (Hughes et al., 2014) it is not inherently problematic, especially when treating a chronic condition.

The indicators of frequency and dose, often used to indicate recreational cannabis dependence, will not necessarily capture medical cannabis dependence as it is important to 'resist the temptation to assume that daily consumption is implicitly problematic' (Asbridge et al., 2014, p. 263). As an example of this, when validating the CUDIT-SF (Bonn-Miller et al., 2016), 100\% of medical cannabis patients endorsed using cannabis every day. Cannabis dependence in this population was best predicted by four CUDIT items: not being able to stop using cannabis once you had started, spending a great deal of time getting, using and recovering from cannabis, and memory/concentration impairment. The internal consistency of the CUDIT-SF was 0.66 for medical patients in the USA and 0.8 in recreational users. In another analysis validating the CUDIT-R (the revised version, from which the CUDIT-SF was derived) in veterans using medical cannabis, Loflin et al. (2018) found that the single factor model of the CUDIT-R previously validated in recreational users only accounted for $38 \%$ of the variance for medical users. These studies suggest that current measures of dependence are not necessarily appropriate for medical cannabis users.

\section{Potency and THC: CBD ratio}

Prolonged use of high-potency cannabis has been associated with dependence and mental health problems in recreational users (Arterberry et al., 2019; Di Forti et al., 2016, 2019; Freeman and Winstock, 2015; Freeman et al., 2018). 'High potency' is commonly judged in research as $>10 \%$ THC. In the medical cannabis literature, higher potency has been associated with more adverse events (Andreae et al., 2015; Wallace et al., 2015; Wilsey et al., 2013). Higher CBD levels in cannabis have been shown to ameliorate cognitive, psychotic- and dependence-related effects of THC (Curran et al., 2016; Englund et al., 2013; Morgan et al., 2010, 2012). A recent comparison of THC and CBD levels available in recreational and medical markets in the USA show that the average THC concentration available in medicinal programmes was $19.3 \%$, similar to recreational programmes where it was $21.5 \%$ (Cash et al., 2020). CBD levels, in contrast, were $2 \%$ and $1.3 \%$ in medical and recreational programmes, respectively (Cash et al., 2020). Given that medical cannabis users are more likely to use cannabis daily, a case could be made for limiting THC in medical cannabis as seen in the Uruguayan market where cannabis sold in pharmacies is under $10 \%$ THC (EMCDDA, 2020).

Ratios of THC: CBD can impact the therapeutic potential, metabolism and side effects of the drug. Direct comparisons of CBMPs suggests that an acute combination of THC: CBD (Sativex) produce less abuse liability effects than synthetic THC (dronabinol) at the same dose (Schoedel et al., 2011). A recent systematic review (Freeman et al., 2019b) suggests some studies have found $\mathrm{CBD}$ can reduce intense experiences of anxiety or psychosis-like effects of THC and blunt potential impairments on emotion and reward processing. However, these effects were not consistently observed and there were high levels of heterogeneity in dose, route and ratio. Importantly this review was of studies with recreational and not medicinal cannabis users. Another recent systematic review reported 11 studies investigating a range of THC:CBD ratios but no clear conclusions could be drawn about dose effects or about the best ratio for safest therapeutic use (Zeyl et al., 2020). Overall, the limited literature suggests that the role of THC:CBD ratio in medical cannabis dependence is not yet clear.

\section{Pharmacokinetics and route of administration}

Pharmacokinetics, the process by which drugs move through the body, is dependent on the route of administration of cannabis. These processes are dynamic, potentially changing over time, and likely affected by the frequency and magnitude of drug exposure. Smoking cannabis is the most common route of administration for recreational users (Hindocha et al., 2016) but is not recommended for medical use because of respiratory concerns. Thus, vaporisers have been used as an alternative. In a placebo-controlled crossover trial in healthy adults who infrequently used cannabis, Spindle et al. (2018) report a comparison of acute effects of smoked vs vaporised cannabis at two doses. They found higher THC concentrations in whole blood following vaporised vs smoked cannabis at both the 10 $\mathrm{mg}$ and $25 \mathrm{mg}$ doses and these demonstrated a dose-related. Such research suggests vaporising may lead to stronger effects than smoking.

Bioavailability of the oral route of cannabinoids is about $6 \%$ (much lower than smoked/vaporised administration), and this is likely because of degradation of the drug in the stomach and significant levels of first-pass metabolism in the liver. The oral route may also reduce the risk of problematic cannabis use although this has not directly been investigated. A comparison of pharmacokinetic parameters can be found in Tables 3 and 4 .

Sativex is an oromucosal spray which has a slower onset than smoking or vaporising cannabis (GWPharma, 2005, 2019). When this method was compared to oral THC (dronabinol) at the same dose, the pharmacokinetic profiles differed (see Tables 3 and 4). Dronabinol had a greater peak plasma THC concentrations with $1.5 \mathrm{~h}$ post-administration as well as a more rapid decline in comparison with Sativex (Schoedel et al., 2011). Sativex is likely to have more than one peak $\left(T_{\max }\right)$ because of early buccal administration followed later by gastrointestinal absorption. There is also greater inter-subject variability between participants. Moreover, both drugs produced lower peak concentrations than smoked cannabis (3.55\% THC) (Huestis et al., 1992) 
and lower subjective effects related to abuse liability (e.g. like drug effect, euphoria) (Cooper et al., 2013).

Together these studies suggest that oral administration routes such as buccal or swallowing is preferred as it could reduce the risk of abuse-related subjective (and neurocognitive) effects (Cooper and Abrams, 2019). However, potential misuse and problematic use of oral cannabinoids have been found in a prospective observational study of 265 patients initiating oral cannabinoid therapy. Ware et al. (2018) compared three measures (Current Opioid Misuse Measure (COMM); Addiction Behaviour Checklist, Chabal Prescription Opioid Abuse Checklist) modified by replacing the word 'opioid' with 'cannabinoid'. At followup, up to a quarter of patients reported problematic prescription oral cannabinoid use on the COMM (Ware et al., 2018). This is important because the COMM is a self-reported and relatively detailed measure of dependence whilst the other measures are short, clinician-rated measures. This potentially suggests that patients have greater worries about medical cannabis dependence than do their clinicians.

Intrapulmonary administration of cannabinoids (e.g. by smoking or vaporising) is considered to be an effective route of administration given its high systemic bioavailability, fast onset of action, short duration of peak effects, and limited duration of effects relative to other methods (e.g. oral or buccal). Moreover, efficient, precise and consistent vaporization delivery systems are under development (Almog et al., 2020). Short drug durations

Table 3. Pharmacokinetics (mean $\mathrm{C}_{\max }$ and $\mathrm{T}_{\max }$ ) of tetrahydrocannabinol (THC) and cannabidiol (CBD) in occasional (noncurrent) users, in blood, after three doses of THC and one dose of CBD.

\begin{tabular}{|c|c|c|c|}
\hline & Smoked & Vaporised & Oral \\
\hline \multicolumn{4}{|c|}{$\begin{array}{l}\text { THC }(10 \mathrm{mg}) \text { (Spindle et al., } 2018 \text { - smoked and vapourised; Vandrey } \\
\text { et al., } 2017 \text { - oral) }\end{array}$} \\
\hline $\mathrm{C}_{\max }(\mathrm{ng} / \mathrm{mL})$ & 3.76 & 7.53 & $1^{\mathrm{a}}$ \\
\hline $\mathrm{T}_{\max }(\mathrm{h})$ & 0.11 & 0.18 & $0.9^{\mathrm{a}}$ \\
\hline \multicolumn{4}{|c|}{$\begin{array}{l}\text { THC }(25 \mathrm{mg}) \text { (Spindle et al., } 2018 \text { - smoked and vapourised; Vandrey } \\
\text { et al., } 2017 \text { - oral) }\end{array}$} \\
\hline $\mathrm{C}_{\max }(\mathrm{ng} / \mathrm{mL})$ & 10.24 & 14.36 & $3.5^{\mathrm{a}}$ \\
\hline $\mathrm{T}_{\max }(\mathrm{h})$ & 0.13 & 0.19 & $2.6^{\mathrm{a}}$ \\
\hline \multicolumn{4}{|c|}{ THC (50.6 mg) (Newmeyer et al., 2016) } \\
\hline THC $C_{\max }(\mathrm{ng} / \mathrm{mL})$ & 51.6 & 47.8 & $10.3^{\mathrm{a}}$ \\
\hline THC $T_{\max }(h)$ & 0.11 & 0.11 & $2.3^{\mathrm{a}}$ \\
\hline \multicolumn{4}{|c|}{ CBD (100 mg) (Spindle et al., 2018) } \\
\hline $\mathrm{CBD} C_{\max }(\mathrm{ng} / \mathrm{mL})$ & $181.4^{b}$ & 104.6 & 11.1 \\
\hline $\mathrm{CBD} \mathrm{T}_{\max }(\mathrm{h})$ & 0.1 & 0.1 & 3 \\
\hline
\end{tabular}

a Oral via a brownie.

bSmoked a high-CBD-dominant strain, which had $100 \mathrm{mg} \mathrm{CBD}$ and $3.7 \mathrm{mg}$ THC. may play a role in medical cannabis dependence in that frequency of use would be greater. Furthermore, rapid drug delivery via smoked or vaporised forms of THC have been linked to greater reinforcement and addiction-related effects for example by promoting forms of neurobehavioural plasticity that contribute to compulsive drug-seeking (Samaha and Robinson, 2005).

\section{Set and setting: the importance of context}

Set, defined as mindset factors (e.g. personality, preparation, expectation and intention of the person involved) and setting, defined as the physical, social and cultural environment in which the drug use takes place (Hartogsohn, 2017), are likely to have an impact of the addictive potential of CBMPs because the result of cannabis consumption is not a linear function of individual dose and dosing (Asbridge et al., 2014). It is possible to consume cannabis regularly and heavily and not experience CUD and current theories of addiction do not address this observation (Temple et al., 2011).

Set and setting are often defined as the non-drug parameters of psychopharmacology (Feldman, 1963) and are often not investigated because including them in clinical drug development would lead to highly complicated trials. Although set and setting are most often discussed in relation to psychedelic research and recreational drug use, its importance for CBMPs should also be investigated. For example, in three studies investigating problematic medical cannabis use, those with a history of psychiatric problems or other drug-use problems (including alcohol), tobacco smokers and recreational cannabis users were more likely to experience medical cannabis dependence (Feingold et al., 2017; Ware et al., 2018). Moreover, in regards to recreational cannabis dependence, van der Pol et al. (2013) found strong evidence pointing to increased risk for CUD among individuals who use cannabis in order to cope with mental distress. Furthermore, the mindset factors for recreational cannabis include the desire to experience the euphoric effects of the drug, whilst for medical cannabis users this is not the desire, indeed many patients discontinue medical use due to these subjective effects (Carotenuto et al., 2020).

Setting differs between medical and recreational cannabis use as well. Medical cannabinoids may be administered in hospitals or other medical environments, whilst recreationally people use cannabis in many different environments. The line between recreational and medical becomes blurred in the home, a common place for both medical and recreational administration. Sociocultural factors may also be at play, for example, in those using black-market cannabis for medical use, the drug may have more harmful implications due to stigma-related factors in comparison to legal, regulated markets.

The context of medicinal and recreational use differ significantly which will have a major impact on the development and

Table 4. Pharmacokinetics (mean Cmax and Tmax) of a single dose of Sativex, Dronabinol and Epidiolex.

\begin{tabular}{|c|c|c|c|c|}
\hline & THC C $\max$ & THC $T_{\max }$ & $\mathrm{CBD}_{\max }$ & $C B D T_{\max }$ \\
\hline Sativex (5.4 mg THC and $5 \mathrm{mg}$ CBD oromucosal spray; Karschner et al., 2011) & 5.1 & 3.3 & 1.6 & 3.7 \\
\hline Dronabinol (5 mg capsule; Parikh et al., 2016) & $2.2^{\mathrm{a}}$ & $1^{\mathrm{a}}$ & & \\
\hline Epidiolex (1500 mg oral solution; Taylor et al., 2018) & & & 292.4 & 4.0 \\
\hline
\end{tabular}


maintenance of dependence. The seminal work of Lee Robins and her colleagues (Robins, 1973; Robins et al., 1974) on heroin addiction among Vietnam veterans shows that many of the key factors in the development and maintenance of addiction go well beyond the simple pharmacology of the drug. These factors were price, availability, how the drug is delivered, the availability of other substances, social norms, education and life circumstances (Hall and Weier, 2016). Robins' studies found high rates of heroin use (34\%) and symptoms of heroin dependence (20\%) among US soldiers while serving in Vietnam. In the first year after returning to the USA, only $1 \%$ became re-addicted to heroin, although $10 \%$ had tried the drug again.

\section{Discussion}

There are notable differences between medical and recreational cannabis users in terms of routes of administration, doses, forms of cannabis as well as set and setting factors. Each of these can significantly affect the potential for dependence. However, there are other factors that we have not explored in this review that require further investigation such as age, ethnicity, cultural factors and concurrent medications. This makes it unjustifiable to directly extrapolate findings from recreational use to medical use. Also because of these differences, the tools traditionally used to assess recreational cannabis dependence are less relevant to measure medical cannabis dependence. Basic research on the prevalence and correlates of medical cannabis dependence is lacking in this new research field which comprises a patchwork of policies regulating medical and recreational use across the globe.

There are still many uncertainties related to medical cannabis and its dependence potential due to the lack of scientific research which resulted from the previous Schedule I status of the drug. After being neglected in the second half of last century, today medical cannabis is increasingly becoming part of the normal pharmacopeia. The development of future research investigating the broad variety of benefits as well as risks associated with the medical use of cannabinoids is essential. It is important to prepare in advance so that issues related to dependence can be addressed in a timely and efficient manner and minimised through effective risk assessment, risk management and policy making. The risks of neglecting this research are evidenced by the tragic- and largely preventable-opioid epidemic in the USA. In relation to medical cannabis, there are a range of key recommendations which can be implemented to help increase/ensure patient safety (see Panel 1).

\section{Limitations and future research}

Not enough is known about medical cannabis users, many of whom are chronic users. Longitudinal data are needed to investigate trajectories of use and potential dependence. Medical users who transition from the black market in comparison to those who begin only when a regulated market was initiated are likely significantly different groups that should be included in the clinical research. Future studies need to examine patient outcomes longitudinally to further understand potential risks including risk factors for dependence.

As most of the research on cannabis dependence has been conducted in relation to recreational use, to date no specific scale
Panel 1. Key recommendations.

1. THC: CBD ratio

As THC in higher doses is associated with dependence whilst CBD appears to have anti-dependence properties it is vital to optimally balance the cannabinoid content of CBMPs to potentially block the development of dependence.

2. Ensure safe supply

It is important that patients are able to access a reliable medical cannabis product rather than having to rely on the black market with its risks and inconsistent products.

3. Develop safer use guidelines

Lower daily cannabis use is associated with better clinical profiles as well as safer use behaviours, i.e. preference for $C B D$ and noninhalation administration routes. This highlights the importance of developing cannabis use guidelines for clinicians to better protect their medical cannabis patients. Evidence-based Lower-Risk Cannabis Use Guidelines (LRCUG) already exist in relation to recreational use (Fischer et al., 2017) and it is imperative to develop these factors focusing specifically on the medical use of cannabis. Risk of dependence might then be mitigated with these factors in mind by physicians giving harm reduction advice and clear clinical guidelines.

4. Screening of patients

It is important to screen for factors which may make an individual more vulnerable to becoming dependent of CBMPs (e.g. previous Substance Use Disorder (SUD)s; current heavy recreational cannabis use). Treatment providers may also need to assess for other (mental) health conditions (e.g. depression and anxiety) when prescribing medical cannabis.

5. Monitoring of use

Potential harms have to be managed e.g. through monitoring (Schlag et al., 2020). Regular monitoring of patients' medical cannabis use is important to stem the development of dependence. This may be done through using a patient registry such as Project TWENTY21 (T21).

6. Personalised medicine

Medical cannabis is a part of the development towards more personalised medicine, and THC: CBD ratios, frequency of use, routes of administration, and subsequent dependence risks will likely differ between conditions and patients. It seems likely that genetic variations in cannabis receptors and metabolism will also be relevant.

7. Balancing patient need and potential for harm

It is essential to balance patient need and the potential for harm. Any risk of medical cannabis dependence needs to be weighed up in relation to alternative medications, some of which have potentially higher abuse liabilities. When prescribing, physicians and patients together need to take this trade-off into consideration, particularly when use is likely to be long-term. It is important to educate patients on the potential risk for dependence and withdrawal. Strategies for reducing dependence (e.g. 'drug holidays' like with methylphenidate treatment; increasing CBD and reducing THC dosages) would need evaluating.

exists to assess medical cannabis dependence. With the increasing use of medical cannabis globally, the development of such a scale is vital. Co-authors of this article $(\mathrm{HVC} / \mathrm{CH})$ are currently developing the Cannabis-Based Medicines Questionnaire (CBMQ) to specifically address problematic medical cannabis use. This questionnaire will be utilised in Project TWENTY21 (the largest UK registry of medical cannabis patients: https://drugscience. org.uk/project-twenty21/), with a high number of respondents over a longitudinal timeframe and the assessment of potential links to predisposing factors, such as the underlying medical 
condition/s. Tracking dependence is challenging and needs to occur in the context of clinical trials as well as careful monitoring of real-world experiences.

\section{Declaration of conflicting interests}

The author(s) declared the following potential conflicts of interest with respect to the research, authorship and/or publication of this article: DJN is Chair of the Scientific Committee of the charity Drug Science, HVC is expert member of Drug Science and RZ is intern at Drug Science. All are voluntary positions. AKS is paid as Head of Research for Drug Science. $\mathrm{CH}$ declares no conflicts of interest

\section{Funding}

The author(s) disclosed receipt of the following financial support for the research, authorship and/or publication of this article: Amongst other funding sources, Drug Science receives an unrestricted educational grant from a consortium of medical cannabis companies. HVC is supported by grants from the UK Medical Research Council (MR/P012728/1) UK Department of Health and by the National Institute for Health Research (NIHR) UCLH Biomedical Research Centre (BRC); she has consulted for Janssen Research and Development. CH is funded by the NIHR BRC and declares no conflicts of interest. Author $\mathrm{CH}$ was employed by GW Pharmaceuticals during the revise and resubmit process. Her substantive contribution to this publication occurred before employment at GW pharmaceuticals.

\section{ORCID iDs}

Anne K Schlag (iD https://orcid.org/0000-0003-2074-1917

Chandni Hindocha (iD https://orcid.org/0000-0003-1692-7401

\section{References}

Allsop D, Lintzeris N, Copeland J, et al. (2015) Cannabinoid replacement therapy (CRT): Nabiximols (Sativex) as a novel treatment for cannabis withdrawal. Clin Pharmacol Ther 97: 571-574.

Allsop DJ, Norberg MM, Copeland J, et al. (2011) The Cannabis Withdrawal Scale development: Patterns and predictors of cannabis withdrawal and distress. Drug Alcohol Depend 119: 123-129.

Almog S, Aharon-Peretz J, Vulfsons S, et al. (2020) The pharmacokinetics, efficacy, and safety of a novel selective-dose cannabis inhaler in patients with chronic pain: A randomized, double-blinded, placebocontrolled trial. Eur J Pain 24: 1505-1516.

American Psychiatric Association (APA) (2013) Diagnostic and Statistical Manual of Mental Disorders. 5th ed. Arlington, VA: American Psychiatric Publishing.

Andreae MH, Carter N, Shaparin K, et al. (2015) Inhaled cannabis for chronic neuropathic pain: A meta-analysis of individual patient data. J Pain 16: 1221-1232.

Argueta D, Ventura C, Kiven S, et al. (2020) A balanced approach for cannabidiol use in chronic pain. Front Pharmacol 11: 561.

Arterberry BJ, Padovano HT, Foster KT, et al. (2019) Higher average potency across the United States is associated with progression to first cannabis use disorder symptom. Drug Alcohol Depend 195: 186-192.

Asbridge M, Duff C, Marsh DC, et al. (2014) Problems with the identification of 'problematic' cannabis use: Examining the issues of frequency, quantity, and drug use environment. Eur Addict Res 20: 254-267.

Bergeria C, Dolan S, Johnson M, et al. (2020) Evaluating the co-use of opioids and cannabis for pain among current users using hypothetical purchase tasks. J Psychopharmacol. Epub ahead of print 12 April 2020. DOI: $10.1177 / 0269881120914211$.

Boehnke K, Scott JR, Litinas E, et al. (2019) High frequency medical cannabis use is associated with worse pain among individuals with chronic pain. J Pain. Epub ahead of print 24 September 2019. DOI: 10.1016/j.jpain.2019.09.006.

Bonn-Miller MO, Bode MT, Bucossi MM, et al. (2014) Self-reported cannabis use characteristics, pattern and helpfulness among medical cannabis users. Am J Drug Alcohol Abuse 40: 23-30.

Bonn-Miller MO, Heinz AJ, Smith EV, et al. (2016) Preliminary development of a brief cannabis use disorder screening tool: The cannabis use disorder identification test short form. Cannabis Cannabinoid Res 1: 252-261.

Borodovsky JT, Crosier BS, Lee DC, et al. (2016) Smoking, vaping, eating: Is legalization impacting the way people use cannabis? Int $J$ Drug Policy 36: 141-147.

Braidwood R, Mansell S, Waldron J, et al. (2018) Non-dependent and dependent daily cannabis users differ in mental health but not prospective memory ability. Front Psychiatry 9: 1-9.

Budney AJ, Hughes JR, Moore BA, et al. (2004) Review of the validity and significance of cannabis withdrawal syndrome. Am J Psychiatry 161: 1967-1977.

Calhoun SR, Galloway GP and Smith DE (1998) Abuse potential of dronabinol (Marinol $\left.{ }^{\circledR}\right)$. J Psychoactive Drugs 30: 187-196.

Carotenuto A, Costabile T, De Lucia M, et al. (2020) Predictors of Nabiximols $\left(\right.$ Sativex ${ }^{\mathbb{R}}$ ) discontinuation over long-term follow-up: A reallife study. J Neurol 267: 1737-1743.

Cash MC, Cunnane K, Fan C, et al. (2020) Mapping cannabis potency in medical and recreational programs in the United States. PLoS One 15: e0230167.

Chester L, Chesney E, Oliver D, et al. (2020) How experimental cannabinoid studies will inform the standardized THC unit. Addiction. Epub ahead of print 5 February 2020. DOI: 10.1111/add.14959.

Choi NG, DiNitto DM and Mart CN (2017) Nonmedical versus medical marijuana use among three age groups of adults: Association with mental and physical health status. Am J Addict 26: 697-706.

Compton WM, Han B, Hughes A, et al. (2017) Use of marijuana for medical purposes among adults in the United States. JAMA 317: 209-211.

Cook S, Lowe J and Martin B (1998) CB1 receptor antagonist precipitates withdrawal in mice exposed to Delta9-tetrahydrocannabinol. $J$ Pharmacol Exp Ther 285: 1150-1156.

Cooper ZD and Abrams DI (2019) Considering abuse liability and neurocognitive effects of cannabis and cannabis-derived products when assessing analgesic efficacy: A comprehensive review of randomized-controlled studies. Am J Drug Alcohol Abuse 45: 580-595.

Cooper ZD, Comer SD and Haney M (2013) Comparison of the analgesic effects of dronabinol and smoked marijuana in daily marijuana smokers. Neuropsychopharmacology 38: 1984-1992.

Curran H, Freeman T, Mokrysz C, et al. (2016) Keep off the grass? Cannabis, cognition and addiction. Nat Rev Neurosci 17: 293-306.

Curran HV, Brignell C, Fletcher S, et al. (2002) Cognitive and subjective dose-response effects of acute oral Delta 9-tetrahydrocannabinol (THC) in infrequent cannabis users. Psychopharmacology 164: 61-70.

Cuttler C and Spradlin A (2017) Measuring cannabis consumption: Psychometric properties of the daily sessions, frequency, age of onset, and quantity of Cannabis Use Inventory (DFAQ-CU). PLoS One 12: $\mathrm{e} 0178194$.

Di Forti M, Marconi A, Carra E, et al. (2016) Proportion of patients in south London with first-episode psychosis attributable to use of high potency cannabis: A case-control study. Lancet Psychiatry 2: 233-238.

Di Forti M, Quattrone D, Freeman TP, et al. (2019) The contribution of cannabis use to variation in the incidence of psychotic disorder across Europe (EU-GEI): A multicentre case-control study. Lancet Psychiatry 6: 427-436.

Droutman V, Read S and Bechara A (2015) Revisiting the role of the insula in addiction. Trends Cogn Sci 19: 414-420.

D’Souza DC, Cortes-Briones JA, Ranganathan M, et al. (2016) Rapid changes in $\mathrm{CB} 1$ receptor availability in cannabis dependent males 
after abstinence from cannabis. Biol Psychiatry Cogn Neurosci Neuroimaging 1: $60-67$.

Edlund MJ, Martin BC, Russo JE, et al. (2014) The role of opioid prescription in incident opioid abuse and dependence among individuals with chronic noncancer pain: The role of opioid prescription. Clin J Pain 30: 557-564.

European Monitoring Centre for Drugs and Drug Addiction (EMCDDA) (2015) Treatment of Cannabis-Related Disorders in Europe. Technical Report. Luxembourg: Publications Office of the European Union.

EMCDDA (2020) Monitoring and Evaluating Changes in Cannabis Policies: Insights from the Americas. Technical Report. Luxembourg: Publications Office of the European Union.

Englund A, Morrison PD, Nottage J, et al. (2013) Cannabidiol inhibits THC-elicited paranoid symptoms and hippocampal-dependent memory impairment. J Psychopharmacol 27: 19-27.

Everitt BJ and Robbins TW (2016) Drug addiction: Updating actions to habits to compulsions ten years on. Annu Rev Psychol 67: 23-50.

Fairman B (2016) Trends in registered medical marijuana participation across 13 US states and District of Columbia. Drug Alcohol Depend 159: 72-79.

Feingold D, Goor-Aryeh I, Bril S, et al. (2017) Problematic use of prescription opioids and medicinal cannabis among patients suffering from chronic pain. Pain Med 18: 294-306.

Feingold D, Brill S, Goor-Aryeh I, et al. (2019) Medical marijuana dependence among chronic pain patients suffering from depression and anxiety. Harefuah 158: 438-444.

Feldman P (1963) Non-drug parameters of psychopharmacology: The role of the physician. In: Rinkel M (ed.) Specific and Non-Specific Factors in Psychopharmacology. New York: Philosophical Library, pp. 149-158.

Fischer B, Russell C, Sabioni P, et al. (2017) Lower-risk cannabis use guidelines: A comprehensive update of evidence and recommendations. Am J Public Health 107: e2-e12.

Freeman T, Morgan C, Hindocha C, et al. (2014) Just say 'know': How do cannabinoid concentrations influence users' estimates of cannabis potency and the amount they roll in joints? Addiction 109: $1686-1694$.

Freeman T and Winstock A (2015) Examining the profile of high-potency cannabis and its association with severity of cannabis dependence. Psychol Med 45: 3181-3189.

Freeman TP, van der Pol P, Kuijpers W, et al. (2018) Changes in cannabis potency and first-time admissions to drug treatment: A 16-year study in the Netherlands. Psychol Med. Epub ahead of print 31 January 2018. DOI: $10.1017 / \mathrm{S} 0033291717003877$.

Freeman TP and Lorenzetti V (2019) Standard THC units': A proposal to standardize dose across all cannabis products and methods of administration. Addiction. Epub ahead of print 9 December 2019. DOI: 10.1111/add.14842.

Freeman TP, Hindocha C, Green SF, et al. (2019a) Medicinal use of cannabis based products and cannabinoids. BMJ 365: 11141.

Freeman AM, Petrilli K, Lees R, et al. (2019b) How does cannabidiol (CBD) influence the acute effects of delta-9-tetrahydrocannabinol (THC) in humans? A systematic review. Neurosci Biobehav Rev 107: 696-712.

Freeman T, Hindocha C, Baio G, et al. (2020) Cannabidiol for the treatment of cannabis use disorder: A phase 2a, double-blind, placebocontrolled, randomised, adaptive Bayesian trial. Lancet Psychiatry 7: 865-874.

Goldstein RZ and Volkow ND (2011) Dysfunction of the prefrontal cortex in addiction: Neuroimaging findings and clinical implications. Nat Rev Neurosci 12: 652-669.

Goulet-Stock S, Rueda S, Vafai A, et al. (2017) Comparing medical and recreational cannabis users on socio-demographic, substance and medication use, and health and disability characteristics. Eur Addict Res 23: 129-135.

Government of Canada (2019) Market Data Under the Access to Cannabis for Medical Purposes Regulations (Archived). Available at: https://www.canada.ca/en/health-canada/services/drugs-medication/ cannabis/licensed-producers/market-data.html (accessed 7 August 2020).

GWPharma (2005) Product Monograph Including Patient Medication Information SATIVEX ${ }^{\circledR}$. Available at: https://www.bayer.ca/omr/ online/sativex-pm-en.pdf (accessed 7 August 2020).

GWPharma (2019) Sativex Oromucosal Spray-Summary of Product Characteristics. Available at: https://www.medicines.org.uk/emc/ product/602/smpc (accessed 7 August 2020).

Hall W and Weier M (2016) Lee Robins' studies of heroin use among US Vietnam veterans. Addiction 112: 176-180.

Haney M, Malcom RJ, Babalonis S, et al. (2016) Oral cannabidiol does not alter the subjective, reinforcing or cardiovascular effects of smoked cannabis. Neuropsychopharmacology 41: 1974-1982.

Hartogsohn I (2017) Constructing drug effects: A history of set and setting. Drug Sci Policy Law 3: 2050324516683325.

Hasin DS, Saha TD, Kerridge BT, et al. (2015) Prevalence of marijuana use disorders in the United States between 2001-2002 and 20122013. JAMA Psychiatry 72: 1235-1242.

Hasin DS, Sarvet AL, Cerda M, et al. (2017) US adult illicit cannabis use, cannabis use disorder, and medical marijuana laws: 1991-1992 to 2012-2013. JAMA Psychiatry 74: 579-588.

Hasin DS, Shnukewitz D, Cerda M, et al. (2020) U.S. adults with pain, a group increasingly vulnerable to nonmedical cannabis use and cannabis use disorder: 2001-2002 and 2012-2013. Am J Psychiatry. Epub ahead of print 22 January 2020. DOI: 10.1176/appi. ajp.2019.19030284.

Hindocha C, Freeman TP, Schafer G, et al. (2015) Acute effects of delta-9-tetrahydrocannabinol, cannabidiol and their combination on facial emotion recognition: a randomised, double-blind, placebo-controlled study in cannabis users. Eur Neuropsychopharmacol 25: 325-334.

Hindocha C, Freeman TP, Ferris JA, et al. (2016) No smoke without tobacco: A global overview of cannabis and tobacco routes of administration and their association with intention to quit. Front Psychiatry 7: 1-9.

Hindocha C, Norberg MM and Tomko RL (2018) Solving the problem of cannabis quantification. Lancet Psychiatry 5: e8.

Huestis MA, Henningfield JE and Cone EJ (1992) Blood cannabinoids. II. Models for the prediction of time of marijuana exposure from plasma concentrations of delta 9-tetrahydrocannabinol (THC) and 11-nor-9-carboxy-delta 9-tetrahydrocannabinol (THCCOOH). $J$ Anal Toxicol 16: 283-290.

Hughes J, Fingar J, Budney A, et al. (2014) Marijuana use and intoxication among daily users: An intensive longitudinal study. Addict Behav 39: 1464-1470.

Justinova Z, Goldberg SR, Heishman SJ, et al. (2005) Self-administration of cannabinoids by experimental animals and human marijuana smokers. Pharmacol Biochem Behav 81: 285-299.

Karschner EL, Darwin WD, Goodwin RS, et al. (2011) Plasma cannabinoid pharmacokinetics following controlled oral delta9-tetrahydrocannabinol and oromucosal cannabis extract administration. Clin Chem 57: 66-75.

Kögel CC, Balcells-Olivero MM, López-Pelayo H, et al. (2017) The standard joint unit. Drug Alcohol Depend 176: 109-116.

Koob GF and Volkow ND (2010) Neurocircuitry of addiction. Neuropsychopharmacology 35: 217-238.

Lin LA, Ilgen MA, Jannausch M, et al. (2016) Comparing adults who use cannabis medically with those who use recreationally: Results from a national sample. Addict Behav 61: 99-103.

Loflin M, Earleywine M and Bonn-Miller M (2017) Medicinal versus recreational cannabis use: Patterns of cannabis use, alcohol use, and cued-arousal among veterans who screen positive for PTSD. Addict Behav 68: 8-23.

Loflin M, Babson K, Browne K, et al. (2018) Assessment of the validity of the CUDIT-R in a subpopulation of cannabis users. Am J Drug Alcohol Abuse 44: 19-23. 
Lopez-Quintero C, de los Cobos JP, Hasin DS, et al. (2011) Probability and predictors of transition from first use to dependence on nicotine, alcohol, cannabis, and cocaine: Results of the National Epidemiologic Survey on Alcohol and Related Conditions (NESARC). Drug Alcohol Depend 115: 120-130.

MacCallum CA and Russo EB (2018) Practical considerations in medical cannabis administration and dosing. Eur J Intern Med 49: 12-19.

Mauro P, Carliner H, Brown Q, et al. (2018) Age differences in daily and nondaily cannabis use in the United States, 2002-2014. J Stud Alcohol Drugs 79: 423-431.

Morgan C, Gardener C, Schafer G, et al. (2012) Sub-chronic impact of cannabinoids in street cannabis on cognition, psychoticlike symptoms and psychological well-being. Psychol Med 42: $391-400$

Morgan CJ, Freeman TP, Schafer GL, et al. (2010) Cannabidiol attenuates the appetitive effects of Delta 9-tetrahydrocannabinol in humans smoking their chosen cannabis. Neuropsychopharmacology 35: 1879-1885.

Muniyappa R, Sable S, Ouwerkerk R, et al. (2013) Metabolic effects of chronic cannabis smoking. Diabetes Care 36: 415-2422.

Murillo-Rodríguez E, Palomero-Rivero M, Millán-Aldaco D, et al. (2011) Effects on sleep and dopamine levels of microdialysis perfusion of cannabidiol into the lateral hypothalamus of rats. Life Sci 88: 504-511.

National Institute for Health and Care Excellence (NICE) (2019) Cannabis-Based Medicinal Products. NICE Guidelines [NG144]. Available at: https://www.nice.org.uk/guidance/ng144 (accessed 11 November 2019).

Nestler EJ (2005) Is there a common molecular pathway for addiction? Nat Neurosci 8: 1445-1449.

Newmeyer MN, Swortwood MJ, Barnes AJ, et al. (2016) Free and glucuronide whole blood cannabinoids' pharmacokinetics after controlled smoked, vaporized, and oral cannabis administration in frequent and occasional cannabis users: Identification of recent cannabis intake. Clin Chem 62: 1579-1592.

Nutt D (2003) Death and dependence: Current controversies over the selective serotonin reuptake inhibitors. $J$ Psychopharmacol 17: 355-364.

Osborne G and Fogel C (2008) Understanding the motivations for recreational marijuana use among adult Canadians. Subst Use Misuse 43: 539-572.

Parikh N, Kramer WG, Khurana V, et al. (2016) Bioavailability study of dronabinol oral solution versus dronabinol capsules in healthy volunteers. Clin Pharmacol 8: 155-162.

Perron BE, Holt KR, Yeagly E, et al. (2019) Mental health functioning and severity of cannabis withdrawal among medical cannabis users with chronic pain. Drug Alcohol Depend 194: 401-409.

Pertwee RG (2008) The diverse CB1 and CB2 receptor pharmacology of three plant cannabinoids: Delta9-tetrahydrocannabinol, cannabidiol and delta9-tetrahydrocannabivarin. $\mathrm{Br} J$ Pharmacol 153: 199-215.

Piper BJ, DeKeuster RM, Beals ML, et al. (2017) Substitution of medical cannabis for pharmaceutical agents for pain, anxiety, and sleep. $J$ Psychopharmacol 31: 569-575.

Reiman A (2007) Medical cannabis patients: Patient profiles and health care utilization patterns. Complement Health Pract Rev 12: $31-50$.

Renard J, Loureiro M, Rosen L, et al. (2016) Cannabidiol counteracts amphetamine-induced neuronal and behavioral sensitization of the mesolimbic dopamine pathway through a novel mTOR/p70S6 kinase signalling pathway. J Neurosci 36: 5160-5169.

Robins LN (1973, September) The Vietnam Drug User Returns: Final Report. Washington, DC: US Government Printing Office.
Robins LN, Davis DH and Goodwin DW (1974) Drug use by US Army enlisted men in Vietnam: A follow-up on their return home. Am J Epidemiol 99: 235-249.

Robson P (2011) Abuse potential and psychoactive effects of $\delta$-9tetrahydrocannabinol and cannabidiol oromucosal spray (Sativex), a new cannabinoid medicine. Expert Opin Drug Saf 10: 675-685.

Roy-Byrne P, Maynard C, Bumgardner K, et al. (2015) Are medical marijuana users different from recreational users? The view from primary care. Am J Addict 24: 599-606.

Samaha A and Robinson T (2005) Why does the rapid delivery of drugs to the brain promote addiction? Trends Pharmacol Sci 26: 82-87.

Schimrigk S, Marziniak M, Neubauer C, et al. (2017) Dronabinol is a safe long-term treatment option for neuropathic pain patients. Eur Neurol 78: 320-329.

Schlag AK (2020) An evaluation of regulatory regimes of medical cannabis: What lessons can be learned for the UK? Med Cannabis Cannabinoids. Epub ahead of print 15 January 2020. DOI: 10.1159/000505028.

Schlag AK, Baldwin DS, Barnes M, et al. (2020) Medical cannabis in the UK: From principle to practice. J Psychopharm 34: 931-937.

Schoedel KA, Chen N, Hilliard A, et al. (2011) A randomized, doubleblind, placebo-controlled, crossover study to evaluate the subjective abuse potential and cognitive effects of nabiximols oromucosal spray in subjects with a history of recreational cannabis use. Hum Psychopharmacol 26: 224-236.

Singh I, Morgan C, Curran HV, et al. (2017) Ketamine treatment for depression: Opportunities for clinical innovation and ethical foresight. Lancet Psychiatry 4: 419-426.

Spindle T, Cone E, Schlienz N, et al. (2018) Acute effects of smoked and vaporized cannabis in healthy adults who infrequently use cannabis. JAMA Netw Open 1: e184841.

Steward JL and McMahon LR (2010) Rimonabant-induced Delta9-tetrahydrocannabinol withdrawal in rhesus monkeys: Discriminative stimulus effects and other withdrawal signs. J Pharmacol Exp Ther 334: 347-356.

Stewart C (2020) Frequency of Medicinal Cannabis Use in the UK 2019|Statista. Statista. Available at: https://www.statista.com/ statistics/1094138/frequency-of-medicinal-cannabis-use-in-theuk/\#statisticContainer (accessed 16 September 2020).

Stith SS, Vigil JM, Brockelman F, et al. (2018) Patient-reported symptom relief following medical cannabis consumption. Front Pharmacol 9: 916.

Straiker A, Dvorakova M, Zimmowitch A, et al. (2018) Cannabidiol inhibits endocannabinoid signaling in autaptic hippocampal neurons. Mol Pharmacol 94: 743-748.

Takakuwa K, Hergenrather J, Shofer F, et al. (2020) The impact of medical cannabis on intermittent and chronic opioid users with back pain: How cannabis diminished prescription opioid usage. Cannabis Cannabinoid Res 5: 263-270.

Taylor L, Crockett J, Tayo B, et al. (2020) Abrupt withdrawal of cannabidiol (CBD): A randomized trial. Epilepsy Behav 104: 106938.

Temple E, Brown RF and Hine DW (2011) The 'grass ceiling': Limitations in the literature hinder our understanding of cannabis use and its consequences. Addiction 106: 238-244.

Tham M, Yilmaz O, Alaverdashvili M, et al. (2018) Allosteric and orthosteric pharmacology of cannabidiol and cannabidiol-dimethylheptyl at the type 1 and type 2 cannabinoid receptors. Br J Pharmacol 176: $1455-1469$.

Turna J, Balodis I, Munn C, et al. (2020) Overlapping patterns of recreational and medical cannabis use in a large community sample of cannabis users. Compr Psychiatry 102: 152188.

United Nations (1971) Convention on Psychotropic Substances. Available at: https://www.unodc.org/pdf/convention_1971_en.pdf

United Nations (2019) Report of the International Narcotics Control Board for 2018. Available at: https://www.incb.org/documents/ 
Publications/AnnualReports/AR2018/Annual_Report/Annual_ Report_2018_E_.pdf (accessed 7 August 2020).

United Nations Office on Drugs and Crime (UNODC) (2015) World Drug Report. United Nations: Office for Drugs and Crime. Available at: https://www.unodc.org/unodc/en/frontpage/2015/June/2015-worlddrug-report-finds-drug-use-stable-access-to-drug-and-hiv-treatmentstill-low.html (accessed 7 August 2020).

United Patients' Alliance (UPA) (2018) UPA Patients' Survey 2018. Available at: https://www.upalliance.org/patient-survey-2018 (accessed 7 August 2020).

UNODC (2017) Responses to Annual Report Questionnaire. United Nations: Office for Drugs and Crime. Available at: https://www. unodc.org/wdr2017/field/Booklet_1_EXSUM.pdf (accessed 7 August 2020).

Van der Pol P, Liebregts N, de Graaf R, et al. (2013) Predicting the transition from frequent cannabis use to cannabis dependence: a three-year prospective study. Drug Alcohol Depend 133(2): 352-359.

Vandrey R, Herrmann ES, Mitchell JM, et al. (2017) Pharmacokinetic profile of oral cannabis in humans: Blood and oral fluid disposition and relation to pharmacodynamic outcomes. J Anal Toxicol 41: 83-99.

Vyas MB, LeBaron VT and Gilson AM (2018) The use of cannabis in response to the opioid crisis: A review of the literature. Nurs Outlook 66: 56-65.

Wade DT, Makela H, House H, et al. (2006) Long-term use of a cannabis-based medicine in the treatment of spasticity and other symptoms in multiple sclerosis. Mult Scler J 12: 639-645.

Wall M, Liu J, Hasin DS, et al. (2019) Use of marijuana exclusively for medical purposes. Drug Alcohol Depend 195: 13-15.
Wallace MS, Marcotte TD, Umlauf A, et al. (2015) Efficacy of inhaled cannabis on painful diabetic neuropathy. J Pain 16: 616-627.

Wang T, Collet JP, Shapiro S, et al. (2008) Adverse effects of medical cannabinoids: A systematic review. Can Med Assoc 178: 1669-1678.

Ware MA, Martel MO, Jovey R, et al. (2018) A prospective observational study of problematic oral cannabinoid use. Psychopharmacology (Berl) 235: 409-417.

Wilsey B, Marcotte T, Deutsch R, et al. (2013) Low-dose vaporized cannabis significantly improves neuropathic pain. J Pain 14: 136-148.

Winstock A, Barratt M, Ferris J, et al. (2017) Global Drug Survey: Key Findings. Available at: https://www.globaldrugsurvey.com/wpcontent/themes/globaldrugsurvey/results/GDS2017_key-findingsreport_final.pdf (accessed 9 September 2020).

Winstock A, Barratt M, Ferris J, et al. (2019) Global Drug Survey: Key Findings. Available at: https://www.globaldrugsurvey.com/wp-content/themes/globaldrugsurvey/results/GDS2019-Exec-Summary.pdf (accessed 9 September 2020).

Woodruff SI and Shillington AM (2016) Sociodemographic and drug use severity differences between medical marijuana users and non-medical users visiting the emergency department. Am J Addict 25: 385-391.

World Health Organization (WHO) (2018) Cannabidiol (CBD) critical review report. In: Expert Committee on Drug Dependence Fortieth Meeting, Geneva.

World Health Organization (WHO) (2019) Review of cannabis and cannabis-related substances. In: Expert Committee on Drug Dependence 41 st Meeting, Vienna.

Zeyl V, Sawyer K and Wightman RS (2020) What do you know about Maryjane? A systematic review of the current data on the THC:CBD ratio. Subst Use Misuse 55: 1223-1227. 